Article

\title{
Analysis and Control of Fault Ride-Through Capability Improvement for Wind Turbine Based on a Permanent Magnet Synchronous Generator Using an Interval Type-2 Fuzzy Logic System
}

\author{
Altan Gencer \\ Department of Electrical and Electronics Engineering, Nevsehir H.B:V. University, Nevsehir 50300, Turkey; \\ altangencer@nevsehir.edu.tr; Tel.: +90-5058-3962-85
}

Received: 24 April 2019; Accepted: 11 June 2019; Published: 15 June 2019

\begin{abstract}
Recently, wind energy conversion systems in renewable energy sources have attracted attention due to their effective application. Wind turbine systems have a complex structure; however, traditional control systems are inadequate in answering the demands of complex systems. Therefore, expert control systems are applied to wind turbines, such as type- 1 and interval type-2 fuzzy logic control (IT-2 FLC) systems. An IT-2 FLC system is used to solve the complexity of the wind turbine system and increases the efficiency of the wind turbine. This paper proposes a new control approach using the IT-2 FLC method applied to a wind turbine based on a permanent magnet synchronous generator (PMSG) to improve the transient stability during grid faults. An IT-2 FLC was designed to enhance the fault ride-through performance of a wind turbine and was implemented to control the machine side converter and grid side converter of a wind turbine. The proposed algorithm performance of a wind turbine based on a PMSG was investigated for different types of grid fault. The analysis results verify that the interval type-2 fuzzy logic control system is robustly utilized under different operational conditions.
\end{abstract}

Keywords: permanent magnet synchronous generator; fault ride-through; interval type-2 fuzzy logic system; wind energy conversion

\section{Introduction}

Due to fluctuations in the price of fossil fuels, the interest in renewable energy sources is increasing day by day [1]. There are many methods of generating electricity from renewable sources, such as the wind turbine and solar panel. Wind turbines are among the most important of these methods. Wind turbines convert wind energy into electrical energy. Many types of generators are used in wind turbines [2]. A permanent magnet synchronous generator (PMSG) has recently begun to attract the attention of wind turbine manufacturers, due to its superior features. The PMSG is supplied to the electrical grid system by means of the grid side converter (GSC), machine side converter (MSC), and control systems [3,4]. The fault ride-through (FRT) capability is one of the important issues for the operation system of the wind turbine. The grid connection requirements (GCRs) involve the operational condition control of the distributed power system [5]. The GCRs have to provide efficiency and reliability to the electrical grid system. The wind turbine (WT) must remain connected to the electrical grid system during grid faults [6]. The fault ride-through is depicted in three stages [7]:

- In the first stage, a WT supplies an electrical power grid system during grid fault time;

- In the second stage, a wind turbine can inject reactive power to support the grid voltage recovery;

- In the third stage, a WT restarts the delivery of the active power after a grid fault. 
All these requirements must be considered in the design of the controller and power converter of the WT. This design increases the stability of the WT during a grid fault [8]. Therefore, many methods are proposed in the literature for the FRT capability enhancement of the PMSG.

A braking chopper (BC) system has been implemented to enhance the FRT capability of a PMSG based on a wind energy conversion system (WECS) during a grid fault [9-12]. This method has some advantages, such as low cost and a simple control structure, but BC does not enhance the power quality in the WT's output. The static synchronous compensator (STATCOM) has been implemented to analyze a dynamic mechanism for a wind farm [13]. A coordinating control system for wind turbines was presented in Reference [13]. However, STATCOM has disadvantages, such as high cost and additional hardware needs. The peak current limitation for a high-power PMSG was realized in Reference [14]. Maximum power point tracking (MPPT) was implemented in the GSC and MSC. An active crowbar is kept the DC link voltage value by using this method. A superconducting fault current limiter (SFCL) was implemented for the FRT enhancement of a PMSG in Reference [15]. The presented method achieved reductions in the fault currents in DC systems.

Recently, soft computing methods have started to develop rapidly with the development of computer technology. Soft computing methods are applied in real-world applications, such as renewable energy and automotive and motor control. Soft computing methods are widely implemented in wind power applications, such as for MPPT control, pitch control, fault diagnosis, wind power generation, wind turbine power control, and prediction of wind speed and power. Soft computing methods consist of four computing algorithms such as predictive method, genetic algorithm, artificial neural networks, and fuzzy logic controllers (Type 1 and Type 2).

Interval type-2 fuzzy logic control (IT-2 FLC) is a type of soft computing method that overcomes the uncertainties of any system [16]. Uncertainty is a natural part of intelligent systems in many applications. Fuzzy Type 1 does not fully deal with the uncertainties of intelligent systems. An IT-2 FLC system is designed to minimize the uncertainties of any system. The IT-2 FLC system has been implemented in industrial applications. For example, interval type-2 hesitant fuzzy sets (IT2HFSs) have been implemented to cope with the underground hydrogen storage site selection problem in Romania [17]. The IT-2 FLC system has been applied in wind power system applications, such as diagnosis, pattern recognition decision, classification, control, and time series prediction.

Mokryani et al. [18] introduced a fault ride-through method using the FLC algorithm for several wind turbines. The presented method was applied to adjust the reactive and active power generated by the generator during grid faults. The proposed algorithm was utilized for all grid fault cases and different locations. Tahir et al. [19] developed a low voltage ride-through (LVRT) method using an adaptive FLC algorithm for wind turbines based on a wound field synchronous generator (WFSG). The proposed method was applied to both power converters of a WT. The proposed control system improved the reactive power of the grid system and regulated the current of the grid side converter. Morshed and Fekih [20] presented a design and analysis of the FRT method for a wind turbine. A new fuzzy second order integral terminal sliding mode control was developed for the power electronic converters. The proposed system was employed in a wind turbine. The overcurrents of the rotor and the stator with the presented control system did not exceed $10 \%$. Therefore, the voltage and current values of the generator were within acceptable ranges. Rashid and Ali [21] proposed to achieve an improved FRT capability based on a fuzzy logic controlled parallel resonance fault current limiter (FLC-PRFCL) for doubly fed induction generator (DFIG)-based wind farms. The effectiveness of the presented protecting control system was compared with conventional proportional-integral (PI) control, the bridge-type fault current limiter, and the crowbar circuit system. Bechkaoui et al. [22] introduced online monitoring of grid faults based on the FLC method for wind plants. The proposed method provided a diagnosis of two grid faults. These faults were open phase and short-circuit. The proposed method was implemented to define the stator condition with high certainty. The data of the whole system were generated under both faulty and healthy conditions. The authors indicate that the proposed method is quite efficient. However, Fuzzy Type 1 does not fully cope with the 
uncertainties of complex systems, such as wind turbines. Several methods have been applied to deal with the uncertainties of complex systems in the literature [23-25]. In addition, in the literature, the interval type-2 FLC has started to be implemented to cope with the uncertainties of complex systems.

Yassin et al. [26] implemented a low voltage ride-through (LVRT) method using an interval type-2 FLC technique for a wind turbine. The input variables of the interval type-2 FLC technique were selected as the DC link voltage and rotor speed. There was irregularity between the delivered to the grid power and the generated active power. To protect from this harmful effect, the proposed method kept the DC link voltage constant. The authors indicate that the proposed algorithm is quite efficient. However, the interval type-2 FLC was implemented only to the MSC control during grid faults. In the normal operational condition, the system was controlled by a traditional control system (PI). The PI control system did not perform better than the IT-2 FLC in any aspect.

This paper proposes a new control approach using the IT-2 FLC method in the WT based on a PMSG to improve the transient stability during grid faults. An IT-2 FLC is designed to enhance the FRT performance of the PMSG. Unlike other studies in the literature, an IT-2 FLC was implemented to control the MSC and GSC of a PMSG during grid faults and normal operational conditions. The aim of the proposed control system is to maintain the generator connected with the grid system and to prevent the harmful effect of an overcurrent occurring during grid faults. The proposed IT-2 FLC is very simple, cost effective, and easy to implement in comparison to the conventional control system. All simulation results proved that the presented IT-2 FLC scheme has the capability to improve the FRT capability of a PMSG.

The rest of the paper is organized as follows: the wind energy conversion system is introduced in Section 2, the proposed protection control system of a PMSG is presented in Section 3, a review of the interval type-2 fuzzy logic system is given in Section 4 , the simulation results validating the proposed methodology are presented in Section 5, and, finally, concluding remarks are provided in Section 6.

\section{Wind Energy Conversion System}

A WECS consists of a blade generator, control system, transformer, point of common coupling (PCC) system, and power electronics components, as shown in Figure 1. Wind turbines convert wind energy into electrical energy. Many types of generators are used in wind turbines. Recently, PMSGs started being used in WTs. Both the GSC and MSC are required to connect wind turbines to the PCC. These converters consist of a neutral point clamped (NPC) system in the study. The NPC three-level converter systems are more effective than conventional converter methods for high-power applications. 


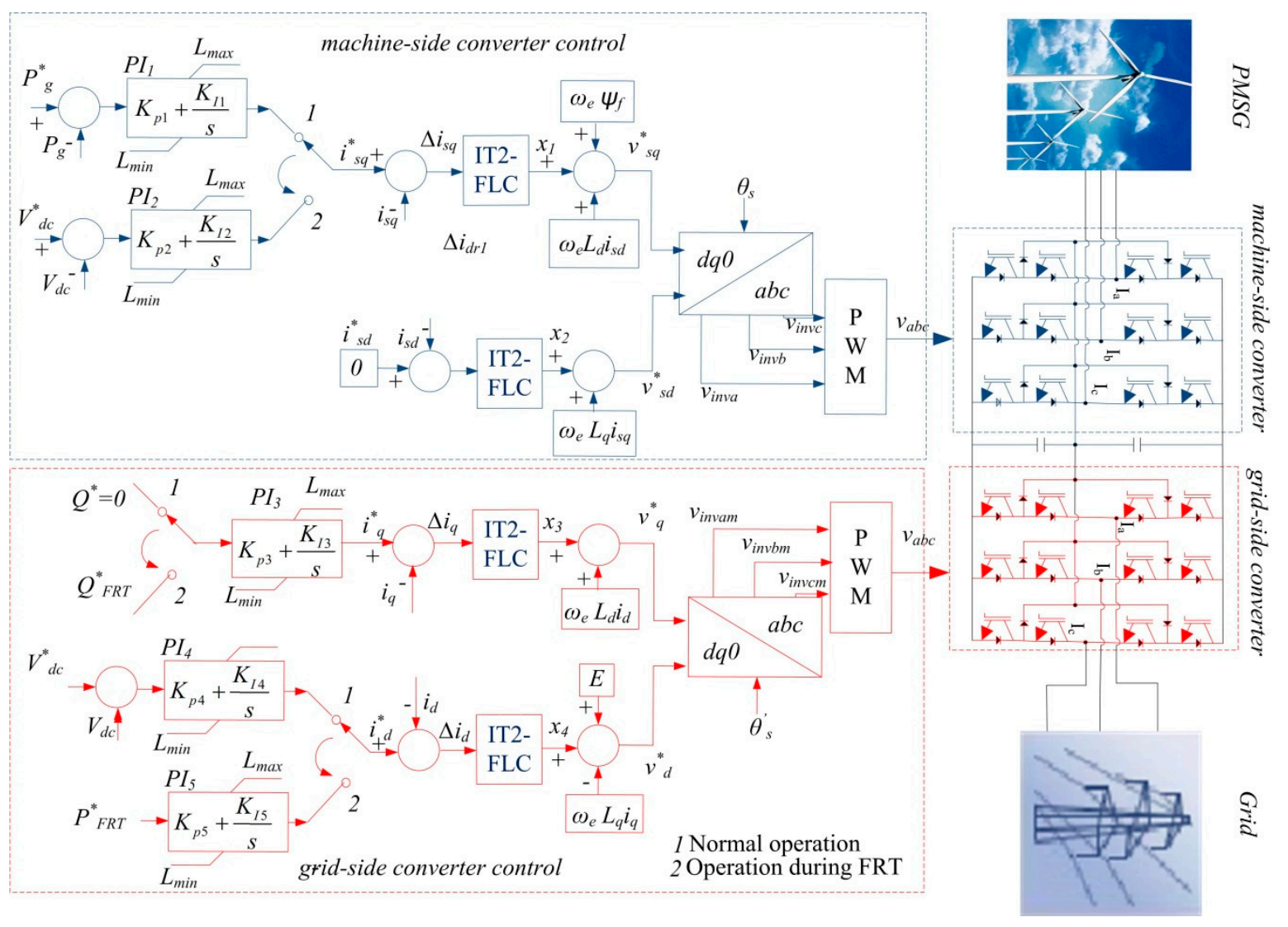

Figure 1. control structure of a permanent magnet synchronous generator (PMSG) based on a wind energy conversion system (WECS).

\subsection{Wind Turbine Characteristics}

The mechanical power of the WT, which converts wind energy into electric energy, is calculated by the following formula [27]:

$$
P_{m}=\frac{1}{2} \rho A C_{p}(\lambda, \beta) V_{\omega}^{3}
$$

where $C_{p}$ is the power coefficient and does not have a constant value. It varies with the tip speed ratio of the WT. $\lambda$, which is the tip speed ratio of the WT, varies the rotational speed of the WT. $\rho$, which is the air density, depends on both air pressure and temperature. $\beta$ denotes the pitch angle. $V_{\omega}$ depicts the wind speed. $A$ represents the area swept by a blade [27]. $\lambda$ is calculated by the formula

$$
\lambda=\frac{\omega_{r} R}{V_{\omega}}
$$

where $\omega_{r}$ depicts the rotor speed and $R$ depicts the blade radius.

The power coefficient $\left(C_{p}\right)$, which is a function of the $\lambda$ and $\beta$, is the most important parameter for the maximum power generated from a wind turbine. This parameter varies for each turbine type. The $C_{p}$ value of each wind turbine is given as the table by the manufacturer. As shown in Equation (1), the maximum active power $\left(P_{m}\right)$ changes linearly with the wind speed.

\subsection{Mathematical Model of Permanent Magnet Synchronous Generator (PMSG)}

The mathematical model of the PMSG is derived from the output voltage equations of the stator. The output voltage equations of the PMSG are illustrated in Equation (3) below. The windings are placed as balanced on the stator. The resistances of the windings are equal and depicted by $R_{s}=R_{q}=R_{d}$. $R_{S}$ depicts the stator resistance, $L_{S}$ depicts the stator inductance, and $\omega_{e}$ denotes the electrical angular 
frequency. $v_{s}$, which depicts an output voltage of the PMSG, is described in Equation (3) [27-30]. The mathematical model is very useful for the generator to operate at optimum values and most important for the safe operation of the generator.

$$
\left(\begin{array}{c}
v_{s d} \\
v_{s q}
\end{array}\right)=R_{s}\left(\begin{array}{c}
i_{s d} \\
i_{s q}
\end{array}\right)+\frac{d}{d t}\left(\begin{array}{c}
L_{d} i_{s d} \\
L_{q} i_{s q}
\end{array}\right)+\omega_{e}\left(\begin{array}{c}
-\psi_{s q} \\
\psi_{s d}
\end{array}\right)
$$

The stator flux linkages ( $d q$ frame) are defined in Equation (4):

$$
\left(\begin{array}{l}
\psi_{s d} \\
\psi_{s q}
\end{array}\right)=\left(\begin{array}{cc}
L_{d} & 0 \\
0 & L_{q}
\end{array}\right) \cdot\left(\begin{array}{c}
i_{s d} \\
i_{s q}
\end{array}\right)+\psi_{f}\left(\begin{array}{l}
1 \\
0
\end{array}\right)
$$

where $\psi_{s d}$ and $\psi_{s q}$ are the flux linkages, $L_{d}$ and $L_{q}$ represent the stator inductances in the $d q$ frame, $i_{s d}$ and $i_{s q}$ represent the generator's $d q$ frame currents, and $\psi_{f}$ represents the flux linkage in the permanent magnets. The $d q$ frame stator voltages by means of the flux linkages are as follows:

$$
\left(\begin{array}{c}
v_{s d} \\
v_{s q}
\end{array}\right)=R_{s}\left(\begin{array}{c}
i_{s d} \\
i_{s q}
\end{array}\right)+\frac{d}{d t}\left(\begin{array}{c}
L_{d} i_{s d} \\
L_{q} i_{s q}
\end{array}\right)+\omega_{e}\left(\begin{array}{c}
-L_{q} i_{s q} \\
L_{d} i_{s d}
\end{array}\right)+\omega_{e}\left(\begin{array}{c}
0 \\
\psi_{f}
\end{array}\right)
$$

where $v_{s q}$ and $v_{s d}$ are the voltages of the $q$ and $d$ loops in the stator, respectively. The voltages of the $v_{s d}$ and $v_{s q}$ are utilized to generate the reference three-phase sinusoidal voltage, and the $i_{s d}$ and $i_{s q}$ depict the currents of the $d$ and $q$ loops in the stator, respectively. $R_{S}$ is a stator resistor, $L_{q}$ and $L_{d}$ represent the inductances of the $q$ and $d$ loops in the stator, respectively, and $\omega_{e}$ is the electrical angular of the PMSG.

\section{Proposed Protection Control System}

The controller design for the PMSG is very important in high performance applications. The design procedure for synthesizing and applying the controllers is very similar to the controllers in other high performance generators. However, the IT-2 FLC has more features than conventional control systems, such as numerical uncertainties and modeling the uncertainties in linguistic variables. The parameters of the PI are difficult to adjust for a WECS based on high nonlinearity with uncertain operating conditions. The PI controller supplies the proper performance for a given operating point. However, new methods have been investigated to overcome numerical uncertainties and new linguistics. The type-2 fuzzy set is a new method with specific characteristics. Thus, the special characteristics of the IT-2 FLC are used to improve wind energy conversion systems in this study. The block diagram for the IT-2 FLC is given in Figure 1. An open source interval type-2 fuzzy logic system (IT2-FLS) Matlab/Simulink (R2106a, MathWorks, Natick, Massachusetts, USA) toolbox produced by Taskin and Kumbasar [31] was used in this study.

The line voltages are measured by the control system in the system runtime. The measurement voltages are compared with the reference voltage. When the measurement current value is higher than the reference current value, the switching mode is changed by the control system. A flowchart of the proposed control algorithm is given in Figure 2.

The $q$ loop of the machine side converter has two switching modes. The first mode is active during normal operation. The first mode input is the active power during normal operation. An error signal is produced by comparing the measured active power $\left(P_{g}^{*}\right)$ with the reference active power $\left(P_{g}\right)$. To obtain the reference current $\left(i_{s q}^{*}\right)$, this error signal is increased by the PI control.

The second mode is active during a grid fault. The input of the second mode is the DC link voltage. An error signal is produced by comparing the reference DC link voltage $\left(V_{d c}\right)$ with the measured DC link voltage $\left(V_{d c}^{*}\right)$. To obtain the reference current $\left(i^{*}{ }_{s q}\right)$, this error signal is increased by the PI control during a grid fault. 


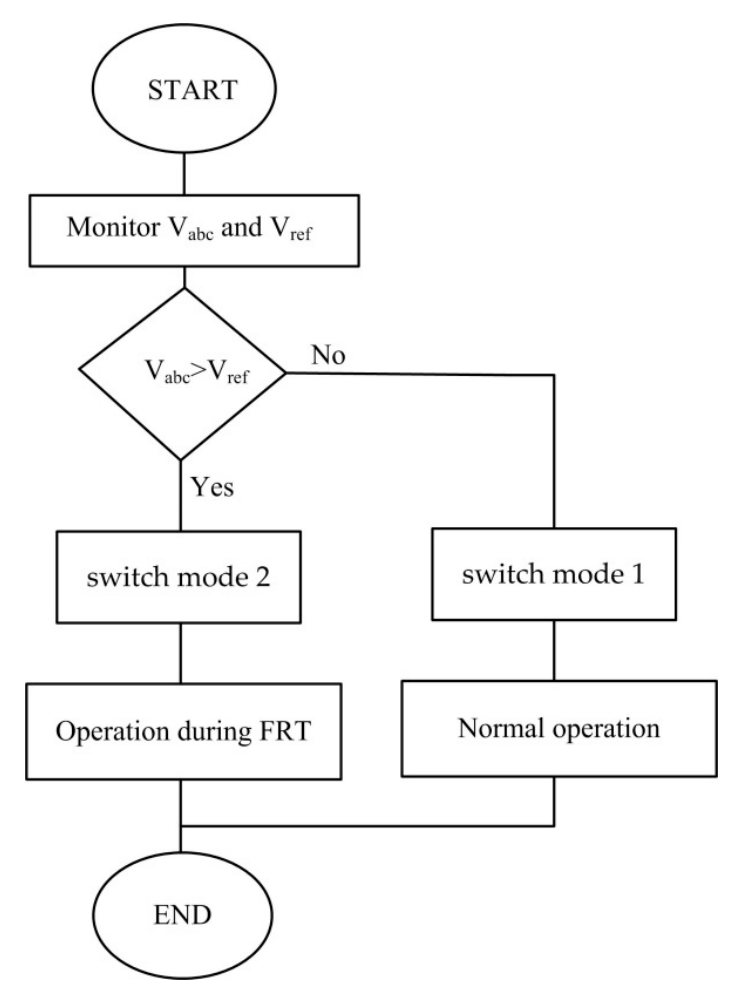

Figure 2. Flowchart of the proposed control algorithm.

$\Delta i^{*}{ }_{s q}$ is produced by comparing the reference current $\left(i^{*}{ }_{s q}\right)$ with the measured current $\left(i_{s q}\right) . \Delta i^{*}{ }_{s q}$ is the input of the IT-2 FLC system for both the fault and normal operations. In this study, the IT-2 FLC was designed specifically to obtain efficient results in both the fault and normal operations. To obtain the required voltage $\left(v_{s q}^{*}\right)$ for switching signals, the IT-2 FLC output signal $\left(x_{1}\right)$ sum with both $\omega_{e} L_{d} i_{s d}$ and $\omega_{e} \psi_{f}$.

In addition, the $d$-axis current reference $\left(i^{*}{ }_{s d}\right)$ of the MSC is set to $0 . \Delta i^{*}$ sd is produced by comparing the reference current $\left(i^{*}{ }_{s d}\right)$ with the measured current $\left(i_{s d}\right) . \Delta i^{*}{ }_{s d}$ is the input of the IT-2 FLC system for both the normal and fault operations. To obtain the required voltage $\left(v_{s d}^{*}\right)$ for switching signals, the IT-2 FLC output signal $\left(x_{2}\right)$ is added to $\omega_{e} L_{q} i_{s q}$.

In Figure 1, the reference voltages $\left(v_{s d}^{*}\right.$ and $\left.v_{s q}^{*}\right)$ are added to enhance the transient response, as expressed by

$$
\left(\begin{array}{c}
v_{s d}^{*} \\
v_{s q}^{*}
\end{array}\right)=\left(\begin{array}{c}
V_{s d}^{\prime} \\
V_{s q}^{\prime}
\end{array}\right)+\omega_{e}\left(\begin{array}{c}
-L_{q} i_{s q} \\
L_{d} i_{s d}
\end{array}\right)+\omega_{e}\left(\begin{array}{c}
0 \\
\psi_{f}
\end{array}\right)
$$

The $q$ loop of the grid side converter has two switching modes. The first mode is active during normal operation. The first mode input is the reactive power during normal operation. The reactive power $\left(Q^{*}\right)$ is set to 0 . To obtain the reference current $\left(i_{q}^{*}\right)$, this error signal is increased by the PI control. The input of the second mode is the fault reactive power $\left(Q_{F R T}^{*}\right)$. To obtain the reference current $\left(i_{q}^{*}\right)$, this error signal is increased by the PI control during a grid fault.

$\Delta i_{q}^{*}$ is obtained by comparing the reference current $\left(i_{q}^{*}\right)$ with the current measured $\left(i_{q}\right) . \Delta i_{q}^{*}$ is the input of the IT-2 FLC system for both the fault and normal operations. In this study, the IT-2 FLC was designed specifically to obtain efficient results in both fault operation and normal operation. To obtain the required voltage $\left(v_{q}^{*}\right)$ for switching signals, the IT-2 FLC output signal $\left(x_{3}\right)$ is added to $\omega_{e} L_{d} i_{d}$.

The second mode is active during the grid fault. The input of the second mode is the active power. To obtain the reference current $\left(i^{*}{ }_{d}\right)$, this error signal is increased by the PI control.

$\Delta i_{d}^{*}$ is produced by comparing the reference current $\left(i^{*}\right)$ with the measured current $\left(i_{d}\right) . \Delta i_{d}^{*}$ is the input of the IT-2 FLC system for both fault and normal operations. In this study, the IT-2 FLC was designed specifically to obtain efficient results in both the normal and fault operations. To obtain the 
required voltage $\left(v_{d}^{*}\right)$ for the switching signals, the IT-2 FLC output signal $\left(x_{4}\right)$ is combined with both the $\omega_{e} L_{q} i_{q}$ and $E$.

In Figure 1, the reference voltages $\left(v^{*} d\right.$ and $\left.v^{*} q\right)$ are added to enhance the transient response, expressed as

$$
\left(\begin{array}{c}
v_{d}^{*} \\
v_{q}^{*}
\end{array}\right)=\left(\begin{array}{c}
V_{d}^{\prime} \\
V_{q}^{\prime}
\end{array}\right)+\omega_{e}\left(\begin{array}{c}
-L_{q} i_{q} \\
L_{d} i_{d}
\end{array}\right)+\left(\begin{array}{c}
E_{s} \\
0
\end{array}\right)
$$

\section{Overview of Interval Type-2 Fuzzy Logic Systems}

The first interval type-2 method was proposed by Zadeh in 1975. Then, many other authors started to implement the IT-2 FLC system in many applications. The IT-2 FLC method consists of five components: fuzzifier, rules, inference engine, type reducer, and defuzzifier. The structure of the IT-2 FLC method is given in Figure 3. The crisp inputs of the IT-2 FLC are obtained from the input sensors. The fuzzifier converts the physical input values into a normalized fuzzy subset. The inference engine of the IT-2 FLC system uses the same rules as those used in a T-1 FLC system. Then, the type reducer converts the IT-2 FLC to a T-1 FLC. Finally, defuzzification is usually called output processing [32]. The fuzzifier is the first stage in applying fuzzy logic control. The fuzzifier converts the physical input values into a normalized fuzzy subset. The physical input values of the sensors are mapped to a set of input fuzzy values $[0,1]$ by the membership functions. Finally, the fuzzifier converts the physical input values to a fuzzy input of the inference engine [33]. The general membership functions of the IT-2 FLC are given in Figure 4.

Type-2 FLC

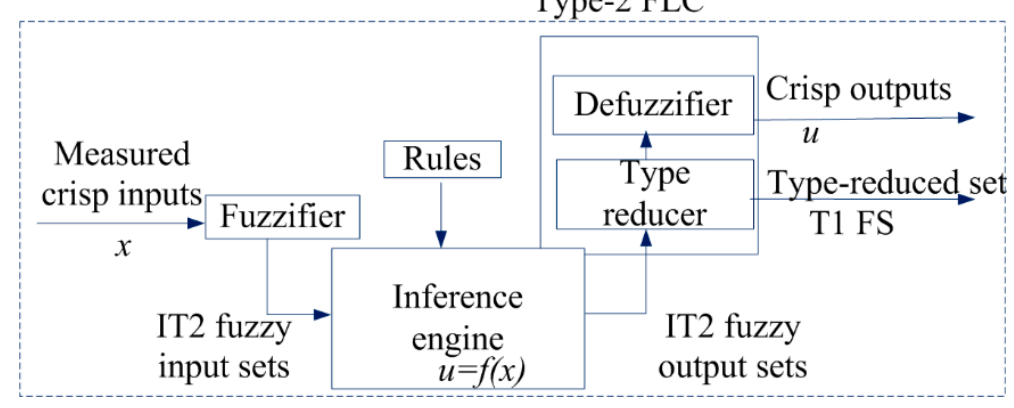

Figure 3. The general structure of the interval type-2 fuzzy logic control.

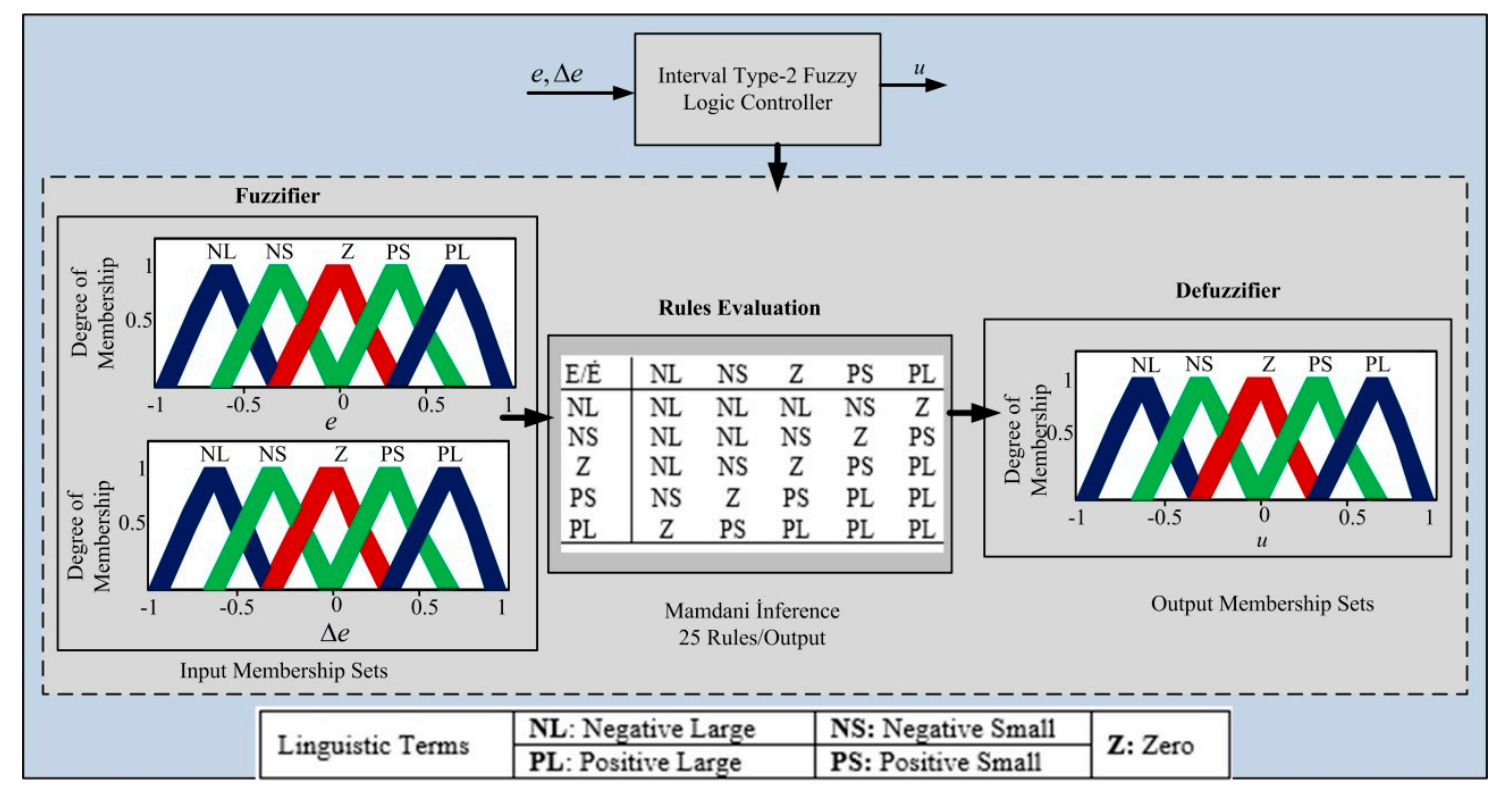

Figure 4. Proposed structure of the interval type 2 fuzzy logic control (IT-2 FLC) system. 
The inference engine is the second stage in applying fuzzy logic control. The inference engine is regarded as a transformer, which from a given input maps an output by using linguistic variables. The inference engine generates functional mapping between the output and the input using fuzzy mapping rules. The inputs of the inference engine are implemented by a set of fuzzy mapping rules (if/then). The fuzzy mapping rules (if/then) decide a given condition using linguistic variables, and, then, the fuzzy sets convert to a set of fuzzy outputs [34,35]. All 25 rules and membership functions for the IT-2 FLC are selected and given in Figure 4. Fuzzy rules are written as follows: if (input1 is membership function1) and/or then (output is output membership function).

Mamdani systems have widespread acceptance, are well suited to human input, and are intuitive. Therefore, the Mamdani system was used in this study.

The defuzzifier is the third stage in applying fuzzy logic control. The defuzzifier converts the fuzzy output available into the control objective. The output of the inference engine is still a linguistic variable. This linguistic variable is transformed into the crisp output by the defuzzifier stage. This stage is regarded as a conversion from the fuzzy output to the crisp output needed for real applications. The mean of the maximum technique, a center of gravity technique, and height techniques are commonly used in defuzzification. The Karnik-Mendel algorithm was implemented in this study as the defuzzification method. The Karnik-Mendel algorithm identifies the largest and smallest elements among the centroids [36]. This method converts fuzzy values into crisp system output values, expressed as

$$
y(x)=\frac{y_{1}+y_{r}}{2}
$$

\section{Simulation Results}

The simulations in this study were realized in Matlab/Simulink to verify the effectiveness and analysis of the presented method. The sampling frequency of the presented Simulink system was modeled at $20 \mathrm{kHz}$. The parameters of the PMSG, turbine, and power converter systems are given in Tables A1-A3, respectively. An open source IT2-FLC toolbox in Matlab/Simulink was used in this study. The rules of the IT-2 FLC system were designed to maximize the power generation from the generator. The IT-2 FLC rules were adjusted to generate the optimized gains for the power performance of the wind system based on the PMSG. An IT-2 FLC control system was implemented for the analysis of three different cases of grid fault. The different types of symmetrical and asymmetrical faults were implemented separately at the proper time on the grid side of the PMSG. The simulated fault conditions were as follows:

(i) The $3 / \phi$ symmetrical fault was implemented at $\mathrm{t}=4.0 \mathrm{~s}$ and was cleared at $\mathrm{t}=4.5 \mathrm{~s}$;

(ii) The $2 / \phi$ asymmetrical fault was implemented at $\mathrm{t}=4.0 \mathrm{~s}$ and was cleared at $\mathrm{t}=4.5 \mathrm{~s}$;

(iii) The $1 / \phi$ asymmetrical fault was implemented at $\mathrm{t}=4.0 \mathrm{~s}$ and was cleared at $\mathrm{t}=4.5 \mathrm{~s}$.

The generator with the proposed control method was connected to the grid during all grid fault types. The simulation results illustrate that the IT-2 FLC system gives an appropriate performance for the power generation of the wind system using a PMSG for different scenarios. The rated value of the DC link was $1150 \mathrm{~V}$, the rated value of active power was 1 p.u., the rated value of the electromagnetic torque power was 1 p.u., and the rated value of the reactive power was 0 p.u. in the study.

\section{Scenario 1}

The $3 / \phi$ symmetrical fault was implemented at $t=4.0 \mathrm{~s}$, and then it was cleared at $\mathrm{t}=4.5 \mathrm{~s}$, as shown in Figure 5a. The $3 / \phi$ symmetrical fault was the severest fault type used. Therefore, the control of this fault type is vital. The IT-2 FLC and T-1 FLC were separately implemented in the WT. The parameters of the WT that were measured were the rotor speed, DC link (Vdc), electromagnetic torque (Te), and reactive and active power. The maximum value of the rotor speed with the T-1 FLC system was 1.4 p.u., and its drop value was $70 \%$ p.u., as shown in Figure 5 b. However, the maximum value of the rotor speed with the IT-2 FLC system was near the nominal value, and the drop value of the rotor speed was 1 p.u., as shown in Figure 5b. The DC link voltage of the system is given in 
Figure 5c. The DC link voltage value using a T-1 FLC system was $1400 \mathrm{~V}$ during the grid fault, while the DC link voltage value with the IT-2 FLC system was near the nominal value. The oscillation of the DC link voltage value with the T-1 FLC system was higher than the proposed control system even after the grid fault time. The active power of the system is given in Figure $5 \mathrm{~d}$. The drop value of the active power with the T-1 FLC was $60 \%$ p.u. and the overshoot value of the active power with the T-1 FLC was 1.25 p.u. However, the active power value with the IT-2 FLC was near the nominal value. The reactive power of the system is given in Figure $5 \mathrm{e}$. The overshoot value of the reactive power with the T-1 FLC system was $40 \%$ p.u. The ripple of the reactive power value with the proposed control system was smaller than the T-1 FLC system. The reactive power value of the IT-2 FLC system was the nominal value both during and after the grid fault. The electromagnetic torque (Te) of the system is given in Figure 5f.

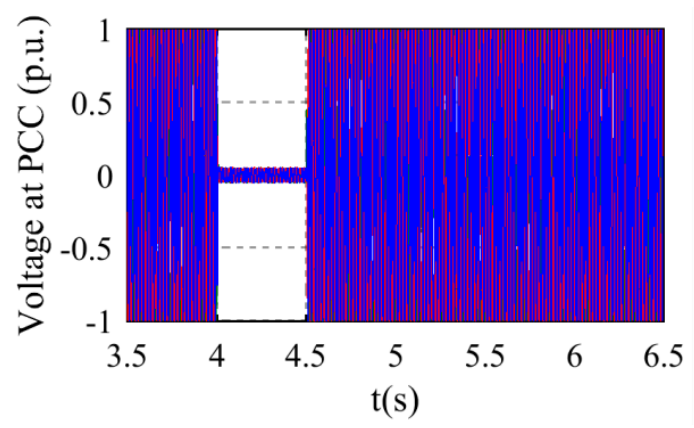

(a)

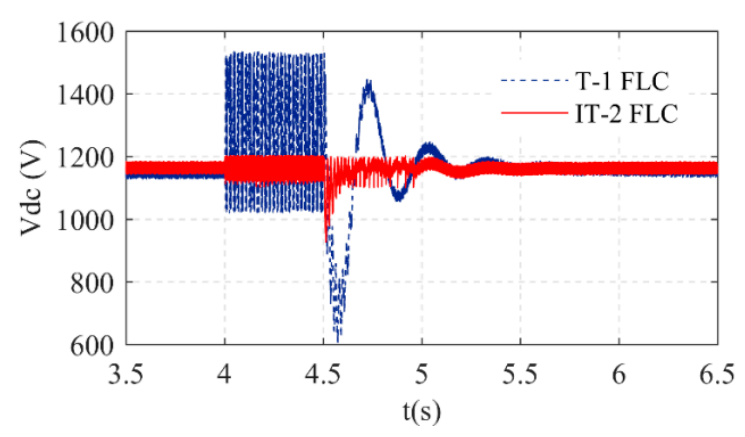

(c)

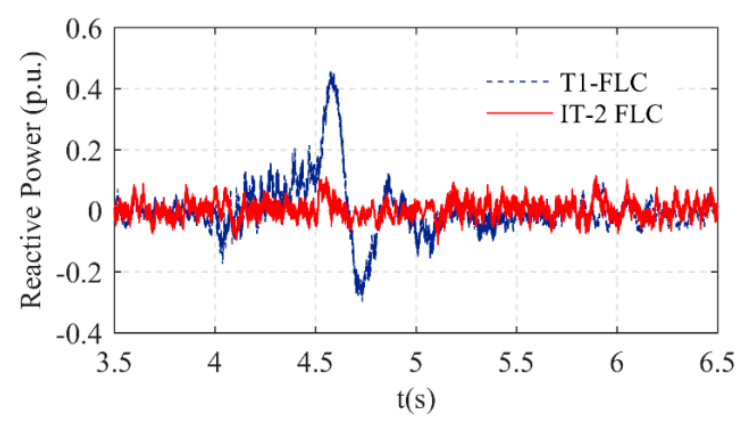

(e)

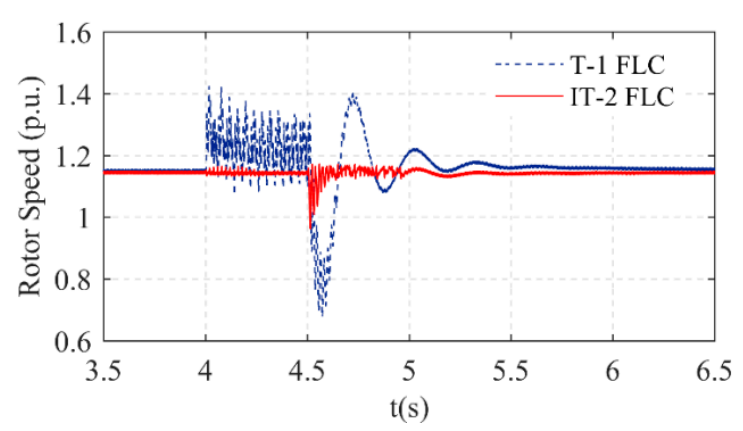

(b)

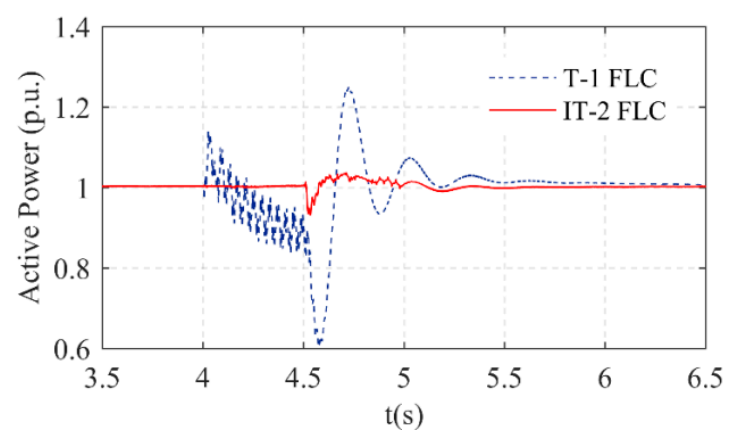

(d)

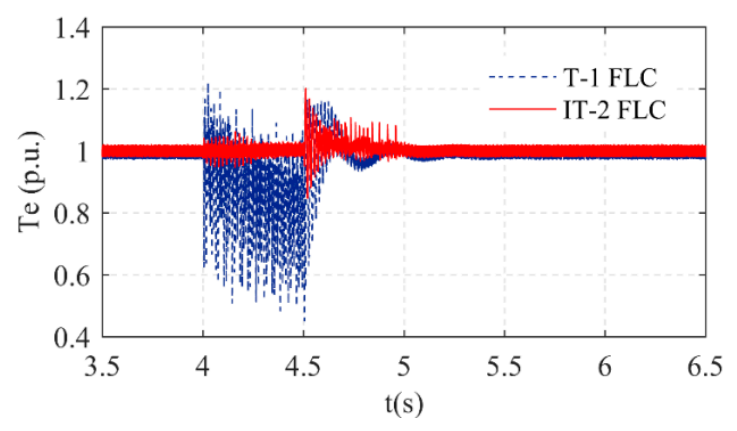

(f)

Figure 5. (a-f). Dynamic response of a 1.5 MVA permanent magnet synchronous generator (PMSG) with the type-1 fuzzy logic control (T-1 FLC) and interval type-2 fuzzy logic control (IT-2 FLC) systems during a $3 / \phi$ symmetrical fault. 
The ripple of the electromagnetic torque value with the proposed control system was smaller than the T-1 FLC system. The electromagnetic torque value with the IT-2 FLC system was the nominal value both during and after the grid fault.

\section{Scenario 2}

The $2 / \phi$ asymmetrical fault was implemented at $\mathrm{t}=4.0 \mathrm{~s}$, and then it was cleared at $\mathrm{t}=4.5 \mathrm{~s}$, as shown in Figure $6 a$. The $2 / \phi$ asymmetrical fault was lighter compared to the $3 / \phi$ symmetrical fault. However, the $2 / \phi$ asymmetrical fault was more severe than the $1 / \phi$ asymmetrical fault. The IT-2 FLC and T-1 FLC were separately implemented in the system during the $2 / \phi$ asymmetrical fault, as shown in Figure $6 \mathrm{a}$. The rotor speed, DC link $\left(V_{d c}\right)$, electromagnetic torque $\left(T_{e}\right)$, and the reactive and active power of the system with the IT-2 FLC had near nominal values and are given in Figure $6 \mathrm{~b}-\mathrm{f}$, respectively. The rotor speed value with the T-1 FLC system increased to 1.4 p.u. in Figure $6 \mathrm{~b}$. The overshoot value of the DC link with the T-1 FLC system was $1400 \mathrm{~V}$. The ripples in the DC link voltage value with the T-1 FLC system were higher than the proposed control system even after the grid fault time. The drop value of the active power with the T-1 FLC was $63 \%$ p.u., and the overshoot value of the active power with the T-1 FLC was 1.21 p.u. The ripple in the active power was greatly reduced by the IT-2 FLC. The reactive power with the T-1 FLC did not track the ideal zero value during the grid fault. The reactive power value with the T-1 FLC was 40\% p.u. during the grid fault. The reactive power value with the proposed control system matched the ideal value perfectly both during and after the grid fault. The ripple of the electromagnetic torque value with the proposed control system was smaller than with the T-1 FLC system.

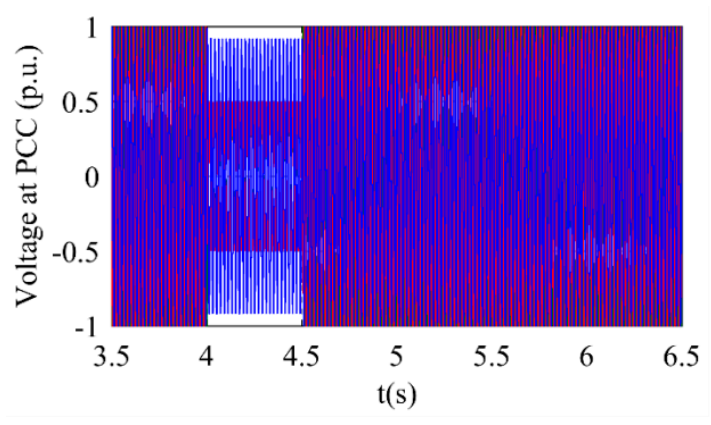

(a)

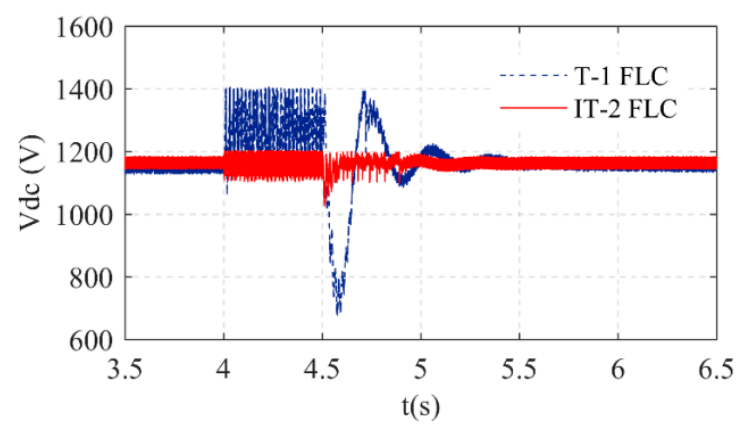

(c)

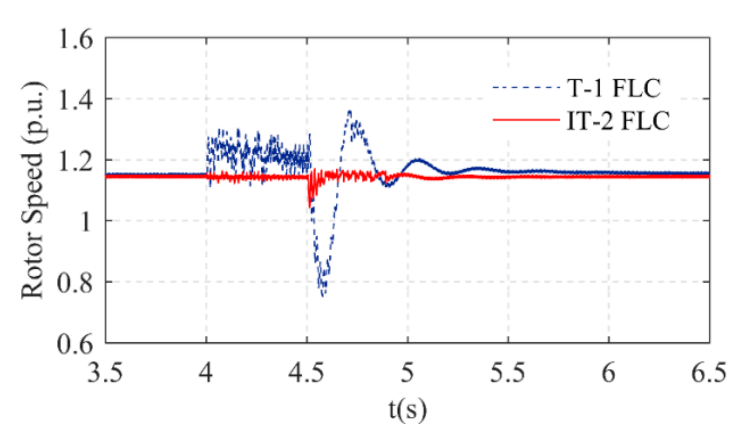

(b)

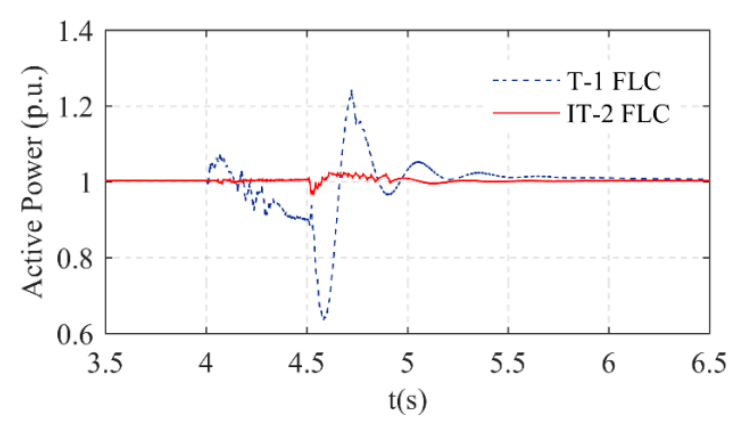

(d)

Figure 6. Cont. 


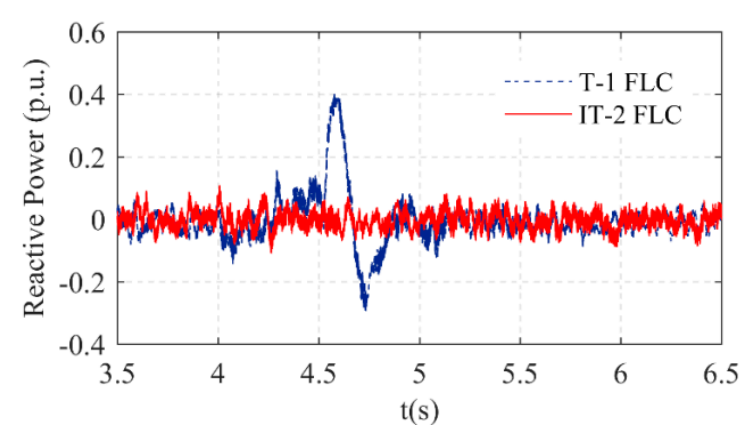

(e)

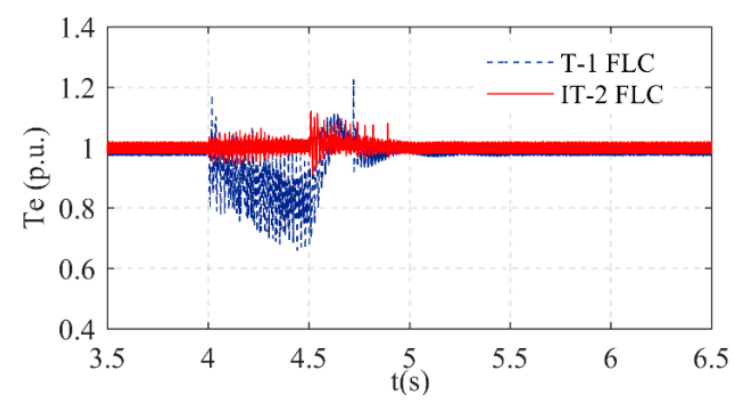

(f)

Figure 6. (a-f). Dynamic response of a 1.5 MVA permanent magnet synchronous generator (PMSG) with the type-1 fuzzy logic control (T-1 FLC) and interval type-2 fuzzy logic control (IT-2 FLC) systems during a $2 / \phi$ unsymmetrical fault.

The electromagnetic torque value with the IT-2 FLC system was the nominal value both during and after the grid fault.

\section{Scenario 3}

The $1 / \phi$ asymmetrical fault was implemented at $\mathrm{t}=4.0 \mathrm{~s}$, and then it was cleared at $\mathrm{t}=4.5 \mathrm{~s}$, as shown in Figure $7 \mathrm{a}$. The $1 / \phi$ asymmetrical fault was lighter than the other fault types. However, the $1 / \phi$ asymmetrical fault is the most common type of grid fault. Therefore, the control of this fault type is vital. The IT-2 FLC and T-1 FLC were separately implemented in the system. The parameters of the system that were measured were the rotor speed, DC link (Vdc), electromagnetic torque (Te), and reactive and active power. The maximum value of the rotor speed with the T-1 FLC system was 1.2 p.u., and its drop value was 1 p.u. value, as shown in Figure $7 \mathrm{~b}$. The DC link voltage with the T-1 FLC system was $1300 \mathrm{~V}$ during the grid fault. The drop value of the active power with the T-1 FLC was $82 \%$ p.u., and the overshoot value of the active power with the T-1 FLC was 1.05 p.u. The parameters of the system that were observed were the rotor speed, DC link $\left(V_{d c}\right)$, electromagnetic torque $\left(T_{e}\right)$, and reactive and active power. The rotor speed, DC link $\left(V_{d c}\right)$, active power, reactive power, and electromagnetic torque $\left(T_{e}\right)$ of the system with the IT-2 FLC had near nominal values and are given in Figure $7 \mathrm{~b}-\mathrm{f}$, respectively. All the parameters of the system with the IT-2 FLC closely tracked the rated values both during and after the grid fault.

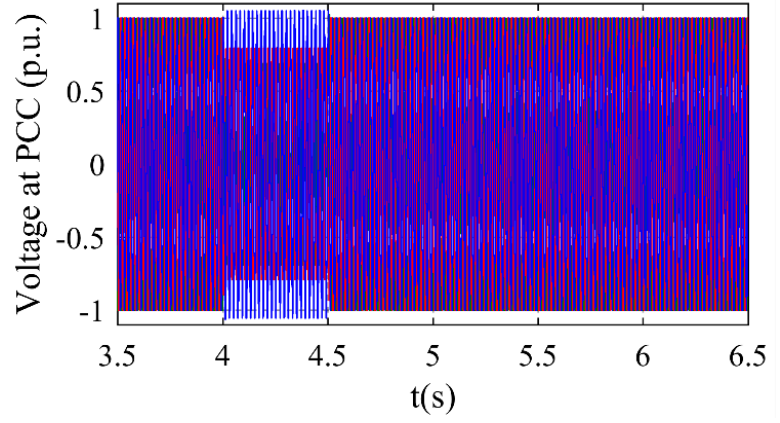

(a)

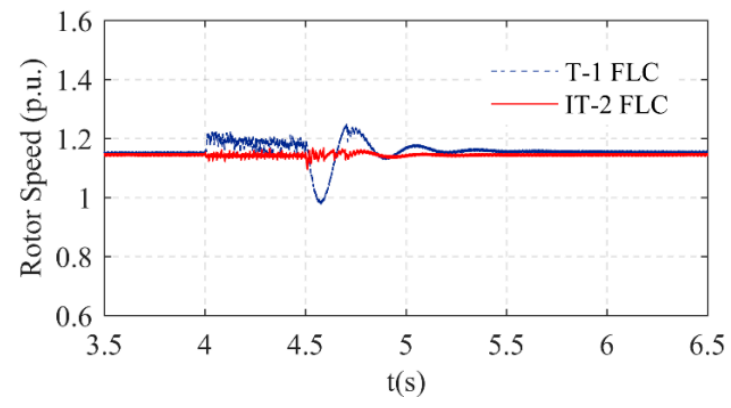

(b)

Figure 7. Cont. 


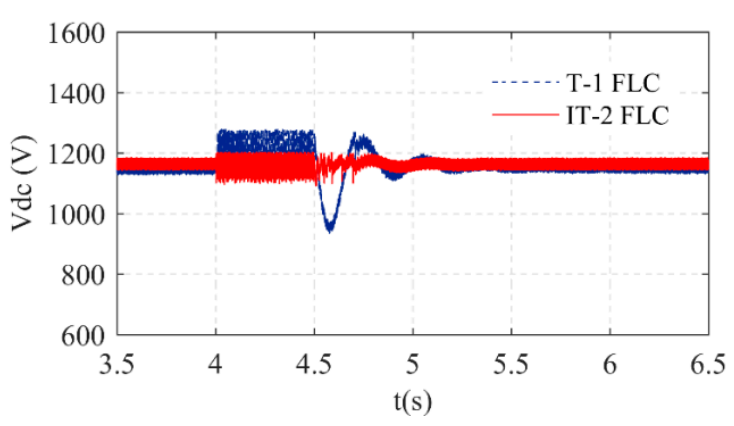

(c)

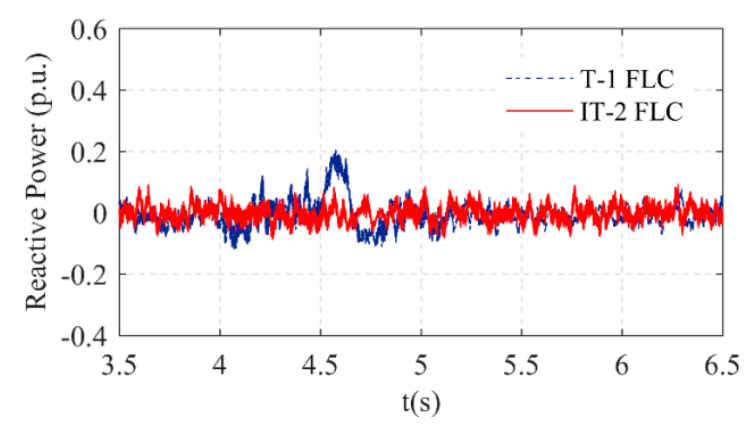

(e)

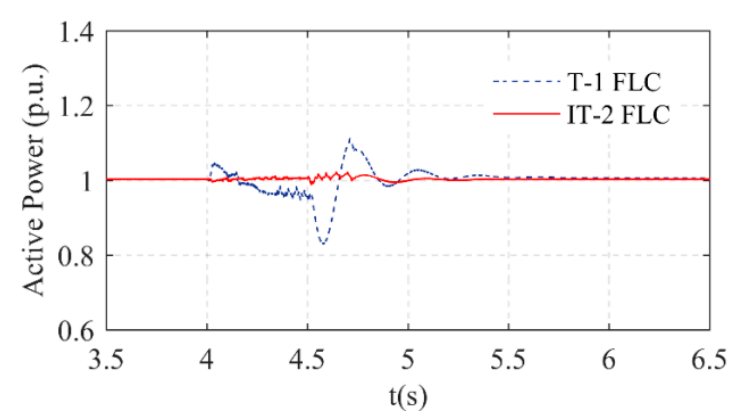

(d)

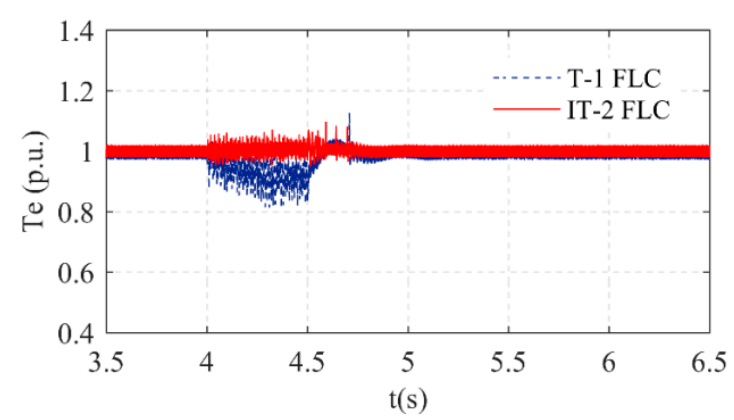

$(\mathbf{f})$

Figure 7. (a-f). Dynamic response of a 1.5 MVA permanent magnet synchronous generator (PMSG) with the type-1 fuzzy logic control (T-1 FLC) and interval type-2 fuzzy logic control (IT-2 FLC) systems during a $1 / \phi$ unsymmetrical fault.

All the parameters with the proposed control system settled to the rated value within comparatively less time than with the T-1 FLC system. The proposed control system reduced the ripples of all the parameters in the system due to the appropriate selection of IT-2 FLC parameters.

\section{Conclusions}

The FRT capability of wind turbines is a vital issue for the electrical energy generated from wind energy and contributes to reliable grid integration. This paper proposes a new control approach using the IT-2 FLC method that is implemented in the WT based on a PMSG to improve the transient stability during grid faults. The main contributions of this work are:

(i) An IT-2 FLC was designed to enhance the fault ride-through performance of the PMSG in order to obtain effective results during grid faults;

(ii) The proposed control system was applied to control the MSC and GSC of the PMSG;

(iii) It was observed by measurements that the proposed control system protects the power electronic devices from the harmful effect of overvoltage during grid faults;

(iv) The simulation results have confirmed that the proposed control system can effectively reduce the ripples of all the parameters in the system. The proposed system also improved the conversion efficiency of the wind turbine system due to the appropriate selection of IT-2 FLC parameters.

The parameters of the system that were observed were the rotor speed, DC link $\left(V_{d c}\right)$, electromagnetic torque $\left(T_{e}\right)$, and reactive and active power. The rotor speed, DC link $\left(V_{d c}\right)$, active power, reactive power, and electromagnetic torque $\left(T_{e}\right)$ of the system with the IT-2 FLC had near nominal values. All the parameters of the system with the IT-2 FLC system closely tracked the rated values during and after the grid faults. All the parameters with the proposed control system settled to the rated value within comparatively less time than the T-1 FLC system. All the simulation results 
proved that the presented IT-2 FLC scheme has the capability to improve the FRT capability of the PMSG and performs better than the T-1 FLC in all aspects.

In the future, the other rule evaluation method (Sugeno) should be applied to the system. In addition, different interval type-2 fuzzy logic control systems, such as the IT-2 FLC PI, can be adapted to improve the FRT performance of wind turbines, and the results can be compared with the results in this paper.

Funding: This research received no external funding.

Conflicts of Interest: The authors declare no conflicts of interest.

\section{Nomenclature}

$\begin{array}{ll}C_{p} & \text { power coefficient } \\ \lambda & \text { tip speed ratio of WT } \\ \rho & \text { air density } \\ \beta & \text { pitch angle } \\ V_{\omega} & \text { wind speed } \\ A & \text { area swept by a blade } \\ \omega_{r} & \text { rotor speed } \\ R & \text { blade radius } \\ R_{S} & \text { stator resistance } \\ L_{s} & \text { stator inductance } \\ \omega_{e} & \text { electric angular of the PMSG } \\ v_{s} & \text { output voltage of the PMSG } \\ \psi_{s d}, \psi_{s q} & \text { flux linkages of the stator windings } \\ \psi_{f} & \text { flux linkage in the permanent magnets } \\ L_{d}, L_{q} & \text { stator inductances in the } d q \text { frame } \\ i_{s d}, i_{s q} & \text { generator } d q \text { frame currents } \\ v_{s q}, v_{s d} & \text { voltages of the } q \text { and } d \text { loops in the stator }\end{array}$

\section{Abbreviations}

$\begin{array}{ll}\text { Acronym } & \text { Definition } \\ \text { PMSG } & \text { Permanent magnet synchronous generator } \\ \text { IT-2 FLC } & \text { Interval type-2 fuzzy logic control system } \\ \text { FRT } & \text { Fault ride-through } \\ \text { GSC } & \text { Grid side converter } \\ \text { MSC } & \text { Machine side converter } \\ \text { GCRs } & \text { Grid connection requirements } \\ \text { STATCOM } & \text { Static synchronous compensator } \\ \text { SFCL } & \text { Superconducting fault current limiter } \\ \text { MPPT } & \text { Maximum power point tracking } \\ \text { DFIG } & \text { Doubly fed induction generator } \\ \text { WT } & \text { Wind turbine }\end{array}$




\section{Appendix A}

Table A1. Parameters of the PMSG.

\begin{tabular}{llll}
\hline \multicolumn{1}{c}{ Parameter } & Symbol & \multicolumn{1}{c}{ Value } & \multicolumn{1}{c}{ Unit } \\
\hline Base power & $P_{b}$ & 1.5 & $\mathrm{MVA}$ \\
Base voltage & $V_{b}$ & 690 & $\mathrm{~V}$ \\
Base frequency & $f_{b}$ & 60 & $\mathrm{~Hz}$ \\
Pole pairs of PMSG & $n_{p}$ & 48 & \\
Rated generator power & $P_{g}$ & 1 & $\mathrm{pu}$ \\
Rated generator speed & $\omega_{r}$ & 1 & $\mathrm{pu}$ \\
Rated generator line voltage & $V_{a b c}$ & 1 & $\mathrm{pu}$ \\
Stator resistance & $R_{s}$ & 0.006 & $\Omega$ \\
Stator inductance & $L_{s}$ & 0.000835 & $\mathrm{H}$ \\
Permanent magnet flux & $\psi_{f}$ & 1.48 & $\mathrm{wb}$ \\
\hline
\end{tabular}

Table A2. Parameters of the turbine.

\begin{tabular}{llll}
\hline \multicolumn{1}{c}{ Parameter } & \multicolumn{1}{c}{ Symbol } & \multicolumn{1}{c}{ Value } & \multicolumn{1}{c}{ Unit } \\
\hline Air density & $\rho$ & 1.225 & $\mathrm{Kg} / \mathrm{m}^{3}$ \\
Area swept by blades & $A$ & 4775.94 & $\mathrm{~m}^{2}$ \\
Base wind speed & $v$ & 12 & $\mathrm{~m} / \mathrm{s}$ \\
Cut-in wind speed & $v_{c}$ & 3 & $\mathrm{~m} / \mathrm{s}$ \\
Optimal power coefficient & $C_{\text {pmax }}$ & 0.4412 & \\
Optimal tip speed ratio & $\lambda_{\text {opt }}$ & 6.9 & \\
\hline
\end{tabular}

Table A3. Parameters of the power converter systems.

\begin{tabular}{llll}
\hline \multicolumn{1}{c}{ Parameter } & \multicolumn{1}{c}{ Symbol } & \multicolumn{1}{c}{ Value } & \multicolumn{1}{c}{ Unit } \\
\hline DC capacitance & $C$ & 10,000 & $\mu \mathrm{F}$ \\
DC link voltage & $V_{d c}$ & 1150 & $\mathrm{~V}$ \\
Grid side filter resistance & $R_{f}$ & 0.027 & $\Omega$ \\
Grid side filter inductance & $L_{f}$ & 1.65 & $\mathrm{mH}$ \\
\hline
\end{tabular}

\section{References}

1. Li, Y.; Xu, Z.; Wong, K.P. Advanced Control Strategies of PMSG-Based Wind Turbines for System Inertia Support. IEEE Trans. Power Syst. 2017, 32, 3027-3037. [CrossRef]

2. Zhang, Z.; Wang, F.; Wang, J.; Rodríguez, J.; Kennel, R. Nonlinear Direct Control for Three-Level NPC Back-to-Back Converter PMSG Wind Turbine Systems: Experimental Assessment with FPGA. IEEE Trans. Ind. Inform. 2017, 13, 1172-1183. [CrossRef]

3. Abdelrahem, M.; Hackl, M.C.; Kennel, R. Simplified model predictive current control without mechanical sensors for variable-speed wind energy conversion systems. Electr. Eng. 2017, 99, 367-377. [CrossRef]

4. Gencer, A. Analysis and control of low-voltage ride-through capability improvement for PMSG based on an NPC converter using an interval type-2 fuzzy logic system. Elektronika ir Elektrotechnika 2019, 25, 3.

5. Alepuz, S.; Calle, A.; Busquets, M.S.; Kouro, S.; Wu, B. Use of Stored Energy in PMSG Rotor Inertia for Low-Voltage Ride-Through in Back-to-Back NPC Converter-Based Wind Power Systems. IEEE Trans. Ind. Electron. 2013, 60, 1787-1796. [CrossRef]

6. Hossain, M.E. A non-linear controller based new bridge type fault current limiter for transient stability enhancement of DFIG based Wind Farm. Electr. Power Syst. Res. 2017, 152, 466-484. [CrossRef]

7. Pulido, A.B.; Romero, J.; Enriquez, H.C. Robust Active Disturbance Rejection Control for LVRT capability enhancement of DFIG-based wind turbines. Control Eng. Pract. 2018, 77, 174-189. [CrossRef]

8. Jerin, A.R.A.; Kaliannan, P.; Subramaniam, U. Improved fault ride through capability of DFIG based wind turbines using synchronous reference frame control based dynamic voltage restorer. ISA Trans. 2017, 70, 465-474. [CrossRef] 
9. Gencer, A. Analysis and Control of Fault Ride Through Capability Improvement PMSG Based on WECS Using Active Crowbar System During Different Fault Conditions. Elektronika ir Elektrotechnika 2018, 24, $64-69$. [CrossRef]

10. Conroy, J.F. Watson Low-voltage ride-through of a full converter wind turbine with permanent magnet generator. IET Renew. Power Gener. 2007, 1, 182-189. [CrossRef]

11. Yang, S.; Zhou, T.; Sun, D.; Xie, Z.; Zhang, X. A SCR crowbar commutated with power converter for DFIG-based wind turbines. Int. J. Electr. Power Energy Syst. 2016, 1, 87-103. [CrossRef]

12. Nasiri, M.; Milimonfared, J.; Fathi, S.H. A review of low-voltage ride-through enhancement methods for permanent magnet synchronous generator based wind turbine. Renew. Sustain. Energy Rev. 2015, 4, 399-415. [CrossRef]

13. Geng, H.; Liu, L.; Li, R. Synchronization and Reactive Current Support of PMSG-Based Wind Farm during Severe Grid Fault. IEEE Trans. Sustain. Energy 2018, 9, 1596-1604. [CrossRef]

14. Nasiri, M.; Mohammadi, R. Peak Current Limitation for Grid Side Inverter by Limited Active Power in PMSG-Based Wind Turbines during Different Grid Faults. IEEE Trans. Sustain. Energy 2017, 8, 3-12. [CrossRef]

15. Yehia, D.M.; Mansour, D.A.; Yuan, W. Fault Ride-Through Enhancement of PMSG Wind Turbines with DC Microgrids Using Resistive-Type SFCL. IEEE Trans. Appl. Supercond. 2018, 28, 1-5. [CrossRef]

16. Zadeh, L.A. The concept of a linguistic variable and its application to approximate reasoning. Inf. Sci. 1975, 8, 43-80. [CrossRef]

17. Iordache, M.; Schitea, D.; Deveci, M.; Akyurt, İ.Z.; Iordache, I. An integrated ARAS and interval type-2 hesitant fuzzy sets method for underground site selection: Seasonal hydrogen storage in salt caverns. J. Pet. Sci. Eng. 2019, 175, 1088-1098. [CrossRef]

18. Mokryani, G.; Siano, P.; Piccolo, A.; Chen, Z. Improving Fault Ride-Through Capability of Variable Speed Wind Turbines in Distribution Networks. IEEE Syst. J. 2013, 7, 713-722. [CrossRef]

19. Tahir, K.; Belfedal, C.; Allaoui, T.; Champenois, G. A new control strategy of WFSG-based wind turbine to enhance the LVRT capability. Int. J. Electr. Power Energy Syst. 2016, 79, 172-187. [CrossRef]

20. Mohammad, J.M.; Afef, F. A new fault ride-through control for DFIG-based wind energy systems. Electr. Power Syst. Res. 2017, 146, 258-269.

21. Gilmanur, R.; Mohd, H.A. Fault ride through capability improvement of DFIG based wind farm by fuzzy logic controlled parallel resonance fault current limiter. Electr. Power Syst. Res. 2017, 146, 1-8.

22. Bechkaoui, A.; Ameur, A.; Bouras, S.; Hadjadj, A. Open-circuit and Inter-turn Short-circuit Detection in PMSG for Wind Turbine Applications Using Fuzzy Logic. Energy Procedia 2015, 74, 1323-1336. [CrossRef]

23. Chybowski, L. Qualitative and Quantitative Multi-Criteria Models of the Importance of the Components in Reliability structure of a Complex Technical system. J. Konbin 2013, 24, 33-44. [CrossRef]

24. Chybowski, L.; Gawdzińska, K. On the Present State-of-the-Art of a Component Importance Analysis for Complex Technical Systems. New Adv. Inf. Syst. Technol. 2016, 445, 691-700.

25. Marczyk, J. Practical Complexity Management; C. Ontonix pub.: Torino, Italy, 2009.

26. Yassin, H.M.; Hanafy, H.H.; Hallouda, M.M. Enhancement low-voltage ride through capability of permanent magnet synchronous generator-based wind turbines using interval type-2 fuzzy control. IET Renew. Power Gener. 2016, 10, 339-348. [CrossRef]

27. Hong, C.-M.; Chen, C.-H.; Tu, C.S. Maximum power point tracking-based control algorithm for PMSG wind generation system without mechanical sensors. Energy Convers. Manag. 2013, 69, 58-67. [CrossRef]

28. Yao, J.; Yu, M.; Gao, W.; Zeng, X. Frequency regulation control strategy for PMSG wind-power generation system with flywheel energy storage unit. IET Renew. Power Gener. 2017, 11, 1082-1093. [CrossRef]

29. Eltamaly, A.M.; Farh, H.M. Maximum power extraction from wind energy system based on fuzzy logic control. Electr. Power Syst. Res. 2013, 97, 144-150. [CrossRef]

30. Calle, P.A.; Alepuz, S.; Bordonau, J.; Cortes, P.; Rodriguez, J. Predictive Control of a Back-to-Back NPC Converter-Based Wind Power System. IEEE Trans. Ind. Electron. 2016, 63, 4615-4627. [CrossRef]

31. Taskin, A.; Kumbasar, T. An Open Source Matlab/Simulink Toolbox for Interval Type-2 Fuzzy Logic Systems. In Proceedings of the IEEE Symposium Series on Computational Intelligence, Cape Town, South Africa, 7-10 December 2015; pp. 1561-1568.

32. Zadeh, L.A. The Concept of a Linguistic Variable and Its Application to Approximate Reasoning; Springer: Berlin, Germany, 1974. 
33. Mendel, J.M. Advances in type-2 fuzzy sets and systems. Inf. Sci. 2007, 177, 84-110. [CrossRef]

34. Mendel, J.M.; Hagras, H.; Tan, W.W.; Melek, W.W.; Ying, H. Introduction to Type-2 Fuzzy Logic Control: Theory and Applications; Wiley: New York, NY, USA, 2014.

35. Mendel, J.M. Uncertain Rule-Based Fuzzy Logic System: Introduction and New Directions; Prentice Hall PTR: Upper Saddle River, NJ, USA, 2001; pp. 131-184.

36. Dongrui, W. Approaches for reducing the computational cost of interval type-2 fuzzy logic systems: Overview and comparisons. IEEE Trans. Fuzzy Syst. 2013, 21, 80-99.

(C) 2019 by the author. Licensee MDPI, Basel, Switzerland. This article is an open access article distributed under the terms and conditions of the Creative Commons Attribution (CC BY) license (http://creativecommons.org/licenses/by/4.0/). 